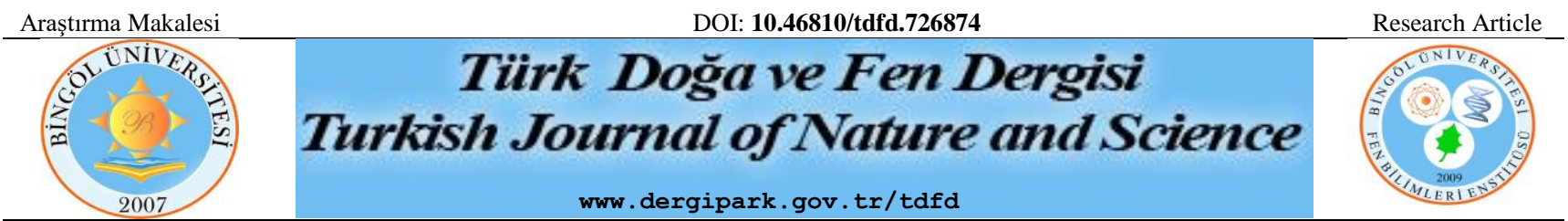

\title{
GNP katkılı Hibrit PVB-TEOS Nanofiberlerin Üretimi ve Karakterizasyonu
}

\author{
$\operatorname{Adem} \mathbf{Y A R}^{1^{*}}$ \\ ${ }^{1}$ Bingöl Üniversitesi, Mühendislik-Mimarlık Fakültesi, Makine Mühendisliği Bölümü, Bingöl, Türkiye \\ Adem YAR ORCID No: 0000-0002-1432-9590 \\ *Sorumlu yazar: ademyar@bingol.edu.tr
}

(Alınış: 25.04.2020, Kabul: 31.05.2020, Online Yayınlanma: 18.06.2020)

\begin{abstract}
Anahtar
Kelimeler

Nanofiber,

Polivinil bütral

(PVB),

Elektro-eğirme

yöntemi,

Tetraetil

ortosilikat (TEOS)

Öz: Polivinil bütral (PVB)/Tetraetil ortosilikat (TEOS) ve PVB/TEOS/ Grafen nanoplatelet (GNP) nanofiberler elektro eğirme yöntemi ile sentezlenmiş ve homojen, boncuksuz bir morfoloji sergilemiştir. PVB, silika bazlı nanofiberler içerisindeki kusurların azalmasını sağlayan öncü polimer olarak kullanılmıştır. PVB/TEOS nanofiberlerin çapları 150-500 nm arasında değişmektedir. $\mathrm{PVB} / \mathrm{TEOS}$ ve $\mathrm{PVB} / \mathrm{TEOS} / \mathrm{GNP}$ nanofiberlerin yapıları ve morfolojileri termogravimetrik analizör (TGA), Fourier dönüşümlü kızılötesi spektrometresi (FTIR) ve taramalı elektron mikroskobu (SEM) analizleri ile incelenmiştir. Analizler, elde edilen nanofiberlerin doku mühendisliği, ilaç salınımı, kanser teşhisi, batarya, sensör ve hava filtresi gibi uygulamalarda nanomalzeme olarak kullanılabileceğini göstermektedir.
\end{abstract}

\section{Fabrication and Characterization of GNP doped Hybrid PVB-TEOS Nanofibers}

\author{
Keywords \\ Nanofiber, \\ Polyvinyl \\ butyral (PVB), \\ Electrospinning \\ method, \\ Tetraethyl \\ orthosilicate \\ (TEOS)
}

\begin{abstract}
PVB/TEOS and PVB/TEOS/GNP (Graphene Nanoplatelet) nanofibers have been synthesized via electrospinning method and exhibit a homogeneous and bead-free morphology. Polyvinyl butyral (PVB) was used as precursor polymer that allows the silica-based nanofiber to diminish of flaws. The average diameter of PVB/TEOS (Tetraethyl orthosilicate) nanofiber ranged from 150 to $500 \mathrm{~nm}$. Structures and morphologies of the PVB/TEOS and PVB/TEOS /GNP nanofibers were examined by Thermogravimetric Analyzer (TGA), Fourier Transform Infrared spectrometer (FTIR) and Scanning Electron Microscopy (SEM). The results demonstrate that the obtained nanofibers can be used as nanomaterials for a wide variety of applications such as tissue engineering, drug delivery, cancer diagnosis, battery, sensors and air filter.
\end{abstract}

\section{GİRIŞ}

Ana Organik-inorganik hibrit malzemeler inorganik fazın termal, kararlılık, rijitlik gibi özellikleriyle organik fazın esneklik, işlenebilirlik, süneklik gibi özelliklerini birleştirdiği için kaplama, biyoteknoloji, ağır metallerin giderimi ve sensör gibi alanlarda kullanım açısından oldukça büyük bir öneme sahip olmaktadır [1, 2]. Bununla birlikte gelişmiş termal ve mekanik özelliklere sahip silika hibrit malzemeler iyi bir esneklik, optiksel saydamlık, su içerisinde kolay bir şekilde dağılım gibi özellikler sergilemektedir. $\mathrm{Bu}$ özelliklerinden dolayı kataliz [3], adsorbsiyon [4], pervaporasyon [5, 6], sensörler [7] ve enzim kapsülleme [8] gibi çeşitli uygulamalarda büyük bir dikkat çekmektedir. Ayrıca silika malzemeler metal katalizörleri desteklemek için de kullanılmaktadır. Çünkü silika malzemelerin nanometre boyutunda ve tüp şeklinde bir yapıya sahip olması yüzey alanının artmasını sağlamaktadır ve bu nedenle katalizör uygulamalarında öngörülmeyen iyileşmelere olanak vermektedir. Aynı zamanda işlevselleştirilmiş mezoporoz silikalar da çift bazlı malzemeler olarak geliştirilme potansiyeline sahip olabilmektedir [9-12].

Polimer-silika hibrit malzemeler yüksek yüzey alanına sahip nano elyaf yapılara dönüştürülerek bu malzemelerin kullanım alanları daha da artmaktadır [1, $4,13]$. Polimer-silika hibrit nano elyaflarını sentezlemek için geliştirilen çeşitli yaklaşımlar arasından elektroeğirme prosesi basit, ucuz ve hızlı olmasından dolayı büyük bir ilgi görmektedir [14-16]. Bu proses elektrostatik alan etkisi altında viskoz bir polimer sıvısından çok ince lifler çeken bir teknik olarak bilinmektedir. Bu teknik ile elde edilen lifler yüksek yüzey alan/hacim oranına sahip olmasından dolayı membran teknolojisi, ilaç dağıtım sistemleri, elektronik, sensör ve enzim immobilizasyonu gibi uygulamalarda kullanılmaktadırlar [10, 17-19]. Ayrıca, sol-jel prosesi ve elektro-eğirme yönteminin birleştirilmesi ile düzgün 
morfoloji, boyut ve bileşime sahip tek boyutlu nanoyapılar kolay bir şekilde sentezlenmektedir [20]. Genellikle, sol-jel yöntemi monolitler, tozlar, tüpler ve fiberler gibi formlarda çeşitli silika bazlı malzemeler hazırlamak için yaygın olarak kullanılmaktadır [21-25]. $\mathrm{Bu}$ yöntem ile hazırlanan çözelti solüsyonun bileşimine ve reaksiyon koşullarına bağlı olarak farklılık gösterebilmektedir. İlaveten, silika bazlı nanofiberler ya viskoz bir çözelti jelinden ya da kuru eğirme yoluyla Tetraetil ortosilikat (TEOS) bazlı çözelti maddelerinden elde edilmektedir [26, 27]. Ayrıca TEOS, PVB polimeriyle kolay bir şekilde karışmaktadır ve bundan dolayı PVB polimeri tercih edilmektedir. PVB ise toksik olmayan, kokusuz ve çevre dostu bir polimer olup ve birçok alanda yaygın olarak kullanılmaktadır. Aynı zamanda inorganik malzemelerle iyi uyumluluğu nedeniyle PVB, organik/inorganik hibrit kompozitlerin üretimi için mükemmel bir organik bileşik olarak görülmektedir [28].

Bu çalışmada inorganik malzemelerin polimer içerisinde kolay bir şekilde dağıtılması ile boncuksuz nanofiberlerin üretimi gerçekleştirildi. PVB/TEOS solüsyonu homojen bir şekilde etanol içerisinde belirli bir sıcaklıkta hazırlandı ve daha sonra elektro- eğirme prosesiyle homojen ve düzgün nanofiberlerin üretimi gerçekleştirildi. PVB polimerine TEOS ilave edilerek elektro-eğirme yöntemiyle elde edilen nanofiberlerin yapısal özellikleri incelendi. Bunun yanı sıra PVB/TEOS solüsyonuna GNP eklenmesi ile morfoloji ve termal kararlılığında meydana getirdiği değişimler SEM, FTIR ve TGA analizleriyle incelendi. Ayrica, GNP ilave edilmesiyle homojen ve boncuksuz bir yapının nasıl elde edildiği ve termal kararlılığın neden düştüğü açıklandı. Aynı zamanda bu çalışmanın amacı nanoparçacıkların nanofiberler ile etkileşimini artırarak sensör, ağır metallerin adsorbsiyonu, filtre gibi uygulama alanlarına olanak sağlamaktır.

\section{MATERYAL VE METOT}

Bu çalışmada kullanılan GNP Nanografi Türkiye'den temin edildi. GNP'ler $\% 99.5$ saflikta olup $150 \mathrm{~m}^{2} / \mathrm{g}$ yüzey alanına sahiptirler. Kalınlığı ise $6 \mathrm{~nm}$ olup çapı $5 \mu \mathrm{m}$ 'dir.

Elektro-eğirme yönteminde kullanılan PVB polimeri Sigma-Aldrich firmasından satın alındı. PVB'nin moleküler ağırlığı 40000- $70000 \mathrm{~g} / \mathrm{mol}$ arasındadır. PVB polimerin camsı geçiş sıcaklığı $72-78{ }^{\circ} \mathrm{C}$ arasında iken erime sıcaklığı $165-185{ }^{\circ} \mathrm{C}$ arasında değişmektedir. Homojen bir şekilde polimer solüsyonunun hazırlanması bu özelliklere bağlıdır. Aynı zamanda TEOS ve etanol Sigma-Aldrich firmasından satın alındı. Soyma kumaşı $83 \mathrm{~g} / \mathrm{m}^{2}$ ağırlığında olup pürüzlü bir yapıya sahiptir. Aynı zamanda çok sıkı dokunmuş naylon esaslı ve silikon kaplı bir yapıya sahiptir.

Polimer solüsyonunun spinlenebilmesi açısından polimer konsantrasyon oranı önemli bir faktör olup nanofiberlerin yapısal ve morfolojik özelliklerini etkilemektedir. $\mathrm{Bu}$ nedenle elektro-eğirme prosesi için PVB polimer konsantrasyon oranı optimize edildi. Daha sonra PVB polimer solüsyonu ağırlıkça \%10 olacak şekilde etanol içerisinde $50^{\circ} \mathrm{C}$ 'de 4 saat boyunca manyetik karıştırıcı ile karıştırıldı [29, 30]. Polimer solüsyonunun karıştırılması sırasında polimer miktarına göre \%50 oranında TEOS ilave edilip karışım homojen ve stabil hale gelene kadar karıştırıldı. Hazırlanan TEOS katkılı PVB polimer solüsyonu steril şırınga içerisine transfer edildi ve otomatik şırınga pompası üzerine yerleştirildi. Toplayıcı ve metalik iğne ucu arasındaki mesafe $15 \mathrm{~cm}$ olacak şekilde ayarland. PVB polimer solüsyonunun akış hızı $0.85 \mathrm{~mL} / \mathrm{h}$ olarak ve diğer bir parametre olan voltaj ise $25 \mathrm{kV}$ olarak belirlendi. Homojenliği sağlaması açısından toplayıcı olarak silindirik mandrel seçililip üzerine kompozit malzeme üretiminde kullanılan soyma kumaşı sarılarak nanofiberlerin toplanması sağlandı. Nanofiberlerin toplanılması esnasında silindirik mandrelin hız1 $400 \mathrm{rpm}$ olarak belirlendi. Toplanan fiberleri kolay bir şekilde soyabilmek için soyma kumaşı tercih edildi. Nanofiberlerin üretimi bu parametrelerde gerçekleştirilerek biriktirildi. Hazırlanan nanofiberler etüvde $40{ }^{\circ} \mathrm{C}$ 'de 30 dakika bekletildi. Aynı yöntem ve parametrelerde $\% 1$ ve $\% 3[31,32]$ oranında GNP katkılı TEOS/PVB nanofiberlerin üretimi gerçekleştirildi. Öncelikle bu numuneler hazırlanırken GNP'ler etanol içerisinde $10 \mathrm{dk}$ boyunca düşük frekanslarda $(15 \mathrm{kHz})$ ultrasonik prob yardımıyla homojen bir şekilde dağıtıldıktan sonra PVB polimeri ve TEOS ilave edilerek solüsyonlar hazırland. Böylece PVB/TEOS, PVB/TEOS/1GNP ve PVB/TEOS/3GNP nanofiber keçeler elde edildi.

Elektro-eğirme yöntemiyle üretilen PVB/TEOS, $\mathrm{PVB} / \mathrm{TEOS} / 1 \mathrm{GNP}$ ve PVB/TEOS/3GNP nanofiberlerin morfolojik özellikleri SEM cihazı ile (ZEISS Evo LS 10) incelendi. GNP, TEOS ile PVB polimer arasındaki bağların titreşiminden faydalanılarak bağ oluşup oluşmadığı FTIR analizi yapılarak incelendi. Elde edilen nanofiberlerin termal özellikleri ise TGA analizleri yapılarak belirlendi.

\section{BULGULAR}

Saf haldeki PVB nanofiberlerin farklı büyütmelerdeki SEM görüntüleri Şekil 1'de gösterilmiştir.

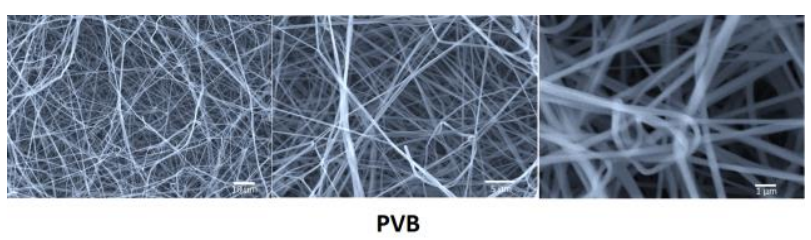

Şekil 1. Saf PVB nanofiberlerin SEM görüntüleri

Elde edilen nanofiberlerin boncuksuz bir yapıda olduğu ve çaplarının 150-400 nm arasında değiştiği gözlenmiştir. Ayrıca bazı fiberlerin kesintili olduğu görülmektedir. $\mathrm{Bu}$ durumun elektro-eğirme esnasında meydana gelen Taylor konisinin kesintiye uğramasından dolayı olduğu söylenebilir. Aynı zamanda görüntülerden elde edilen nanofiberlerin homojen ve girift halde olduğu anlaşılmaktadır. 
Şekil 2'de elektro-eğirme yöntemiyle üretilen PVB/TEOS, PVB/TEOS/1GNP ve PVB/TEOS/3GNP nanofiberlerin farklı büyüklüklerdeki morfolojilerine ait SEM görüntüleri verilmiştir. SEM görüntülerine bakıldığında nanofiberlerin homojen ve boncuksuz bir yapıda olduğu anlaşılmaktadır. Parametreler optimize edildikten sonra PVB/TEOS, PVB/TEOS/1GNP ve $\mathrm{PVB} / \mathrm{TEOS} / 3 \mathrm{GNP}$ nanofiberlerin üretimi gerçekleşmiştir. Nanofiber üretimi süresince kullanılan çözücünün hızlı bir şekilde buharlaşması fiber oluşumunu hızlandırırken meydana gelen nanofiberlerin daha düşük kristalli bir yapıda olmasına neden olmaktadır. Başka bir ifadeyle hızlı katılaşma ve çözücünün buharlaşması polimerin yapısındaki kristalizasyon yapısını azaltarak polimerin zincir yönlenmesini etkilememektedir [33].

PVB/TEOS nanofiberlerin SEM görüntülerine bakıldığında homojen ve boncuksuz bir yapıya sahip olduğu ve nanofiberlerin çapları $150-500 \mathrm{~nm}$ arasında değiştiği görülmektedir. PVB polimerinin uzun zincirli bir yapıya sahip olması homojen ve boncuksuz bir yapının oluşmasında önemli bir rol oynamaktadır. Polimer solüsyonunun konsantrasyon oranı arttığında polimer zincir sarmal yapıların yüksek olmasından dolayı viskozite artmakta ve buna bağlı olarak da PVB/TEOS nanofiberleri uniform bir yap1 sergilemektedir. Ancak viskozitenin artmas1 nanofiberlerin iletkenliğini azaltmaktadır. Yüksek viskoziteli çözücü iyon difüzyonunu engelleyerek iletkenliği azaltmaktadır [34]. Çözelti iletkenliği elektroeğirme prosesinde temel parametrelerden biridir. Çünkü viskoz polimer çözeltisi yüzeydeki mevcut olan yüklerin iletilmesinden dolayı uzayarak gerilir ve daha fazla solüsyon daha fazla yük iletkenliğinde taşınabilir [35]. Ayrıca, uzun moleküler zincire sahip olan PVB polimeri solüsyona ilave edildiğinde hem TEOS hem de PVB polimerinde silanol gruplarının (Si-OH) çapraz yoğunlaştırılması yoluyla kovalent bağlar oluşturarak daha küçük silika sol molekülleri ile sarmal bir yapı oluşturma eğilimindedir [36].

Viskozitenin dışında çözeltinin yüzey gerilimi ve iletkenliği elektro-eğirme yapma kabiliyetini belirlemektedir. Çözeltinin yüksek yüzey gerilimine sahip olması nanofiberlerin boncuklu bir yap1 oluşturmasına yol açar. TEOS-PVB çözeltilerinin yüzey gerilimi PVB içeriğiyle ilgilidir. PVB içeriğinin artmasıyla birlikte çözeltilerin yüzey gerilimi de artmaktadır. SEM görüntülerine bakıldığında nanofiberlerin homojen olduğu ve boncuklu yap1 oluşmadığı görülmektedir. Daha yüksek bir PVB yüzdesinin ve GNP'nin neden olduğu iletkenlikteki artış Raileigh kararsızlığın azaltılmasında önemli bir rol oynamakta ve yüzey gerilimdeki artışa rağmen boncuksuz nanofiberlerin oluşumunu kolaylaştırdığ görülmektedir. PVB/TEOS solüsyonuna $\% 1$ ve $\% 3$ oranında GNP ilave edilmesiyle nanofiber morfolojisi benzer özellik göstermekte ve nanofiber çapları 150-400 nm arasında değişmektedir. Nanofiberlerin homojen bir yapıda olması GNP'lerin solüsyonun iletkenliğini artırarak jet oluşumu esnasındaki kararsızlığı azaltmasından dolayıdır. Çünkü GNP'ler yüksek elektrik iletkenliği, yüksek modül, spesifik yüzey alanı ve yük aktarım kapasitesi gibi önemli özelliklere sahiptir [37].

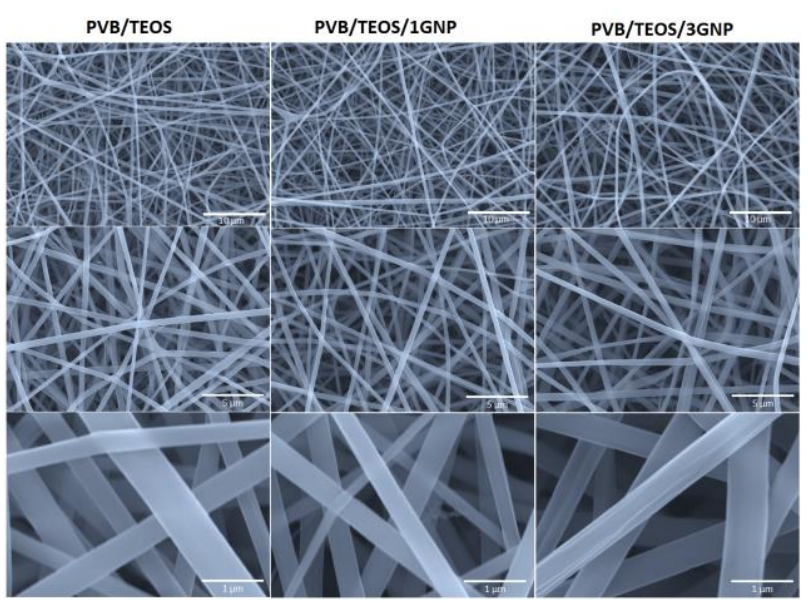

Sekil 2. PVB/TEOS, PVB/TEOS/1GNP ve PVB/TEOS/3GNP nanofiberlerin SEM görüntüleri

Nanofiberleri oluşturan PVB, TEOS ve GNP arasındaki bağ etkileşimlerini incelemek için Şekil-3'de gösterilen FTIR spektrum analizi gerçekleştirilmiştir. FTIR spektrumları incelendiğinde GNP katkılı nanofiberlerin spektrumları ile TEOS katkılı nanofiberlerin spektrumları birbiriyle kıyaslandığında yeni piklerin oluşmadığı veya kaybolmadığı anlaşılmaktadır. Aynı zamanda GNP/TEOS ilavesinin polimer malzemeyle herhangi bir bağ oluşumu olmadığı görülmekte ve gerçekleşen FTIR analizlerinde GNP ve TEOS ilavelerinin katkı yapılmasıyla pik şiddetlerinde değişimler, dalga sayılarında az da olsa değişikliklerin olduğu görülmektedir. Ancak \% 1 oranında GNP'nin polimere katk1 yapılması ile PVB/TEOS nanofiberlerin pik şiddetine nazaran bir artış meydana geldiği ve GNP miktarının artmasıyla birlikte pik şiddetinde bir azalma meydana geldiği görülmektedir. Çünkü GNP miktarının artmasıyla birlikte polimer konsantrasyon oranını da artmaktadır. Bundan dolayı amorf bir yap1 meydana gelmiştir. Amorf yapının meydana gelmesi pik şiddetinin düşmesine yol açmaktadır. 800 ve $957 \mathrm{~cm}^{-1}$ dalga sayısındaki piklerin varlığı sırasıyla $\mathrm{Si}-\mathrm{O}-\mathrm{Si}$ ve $\mathrm{Si}-\mathrm{OH}$ bağlarını göstermektedir [38]. $1000 \mathrm{~cm}^{-1}$ dalga sayısındaki pikler $(\mathrm{C}-\mathrm{H})$ bağlanmalarını, $1050 \mathrm{~cm}^{-1}$ dalga sayısındaki pikler (Si-O-Si) bağlanmalarını [38, 39] , $1132 \mathrm{~cm}^{-1}$ dalga sayisindaki pikler (C-O-C) bağlanmalarını, $1276 \mathrm{~cm}^{-1}$ dalga sayısındaki pikler (Si$\left.\mathrm{CH}_{3}\right)$ [40], $1350 \mathrm{~cm}^{-1}$ dalga sayisindaki pikler $\left(-\mathrm{CH}_{2}\right)$ bağlarını, $2874 \mathrm{~cm}^{-1}$ dalga sayısındaki pikler $(\mathrm{C}-\mathrm{H})$ bağlarını, $2950 \mathrm{~cm}^{-1}$ dalga sayısındaki pikler $(-\mathrm{CH}$, $\mathrm{CH}_{2}$ ) bağlarını, göstermektedir. FTIR spektrum analizi incelendiğinde dalga sayısında da kaymaların meydana geldiği görülmektedir. Bunun nedeni GNP'lerin nanofiber içerisinde olduğu ve polimer yapıyla hidrojen bağları oluşturduğu anlaşılmaktadır. $3430 \mathrm{~cm}^{-1}$ dalga sayısındaki pikler $-\mathrm{OH}$ bağlanmalarını temsil etmektedir [41]. 


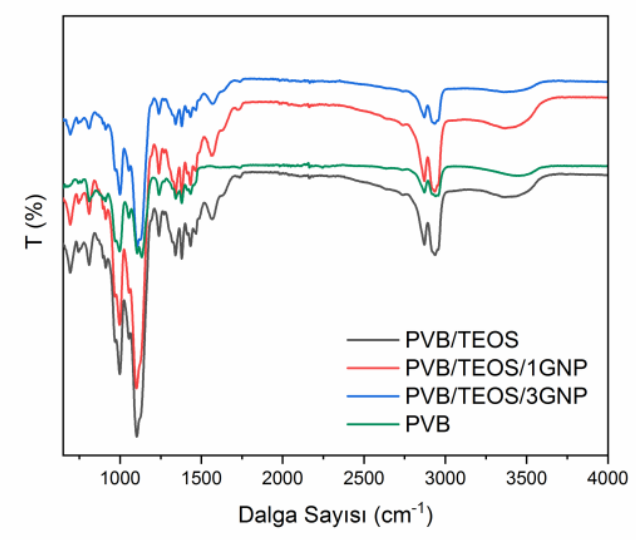

Şekil 3. Üretilen nanofiberlerin FTIR spektrumları

PVB/TEOS, PVB/TEOS/1GNP ve PVB/TEOS/3GNP nanofiberlerin termal bozulma davranışlarını ölçmek için TGA analizleri kullanılmıştır. Analizler $\mathrm{N}_{2}$ atmosferi altında $10{ }^{\circ} \mathrm{C} / \mathrm{min}$ isıtma hızı ile $25^{\circ} \mathrm{C}$ 'den $1000{ }^{\circ} \mathrm{C}$ 'ye kadar gerçekleştirilmiştir. PVB/TEOS nanofiberin iki aşamada ayrıştığı TGA analizinden anlaşılmaktadır. Şekil 4. incelendiğinde $300{ }^{\circ} \mathrm{C}$ sicaklığa kadar kütle kaybının düşük olduğu bu sıcaklık değerinden sonra 500 ${ }^{\circ} \mathrm{C}$ sıcaklığa kütle kaybının yüksek olduğu görülmektedir. İlk aşamada hidroksil gruplarının 200 ile $330{ }^{\circ} \mathrm{C}$ arasındaki sıcaklıklarda parçalanması ve sonraki aşamada ise $350{ }^{\circ} \mathrm{C}$ 'den yüksek sıcaklıklarda bütiralin ayrışması gerçekleşmektedir. PVB'nin azot atmosferi içerisindeki termal bozulması suyun ve bütanalın salınmasina neden olmaktadır. Asetat gruplar 390 ${ }^{\circ} \mathrm{C}$ 'den yüksek sıcaklıklarda serbest kalmaktadır.

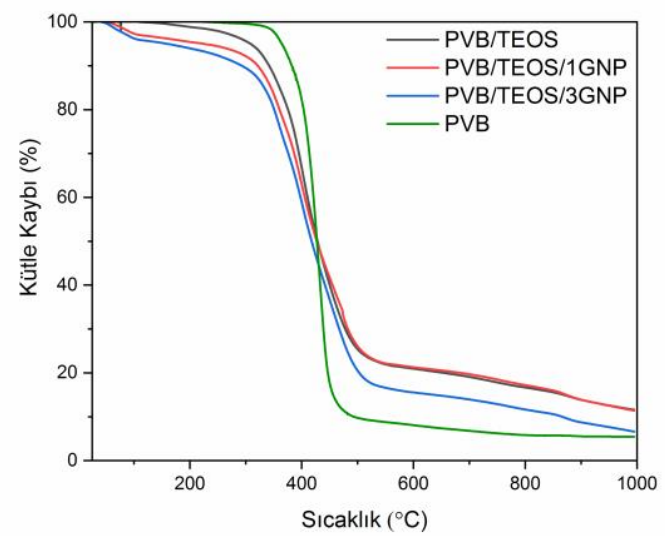

Şekil 4. Üretilen nanofiberlerin termogravimetrik analizleri (TGA)

PVB'nin 1sıl bozulmasından sonra karbon kalıntıları geride bırakılmıştır. Nanofiberler, azot atmosferinde bozulmayan karbon atıkları ve grafen nanoplateleri içermektedir. PVB'nin parçalanmasındaki temel bozulma basamağı, bütiralin ortadan kaldırılarak bütanalın oluşma sürecini kapsamaktadır [42, 43]. TGA analizinde bütiral halkalarının ayrışma sıcaklığı 350 ${ }^{\circ} \mathrm{C}$ 'dir. TGA termografiğinden, PVB/TEOS/1GNP ve PVB/TEOS/3GNP nanofiberlerin $200-300{ }^{\circ} \mathrm{C}$ arasında daha düşük termal kararlılığa sahip oldukları görülmektedir. Kullanılan çözücünün hacmi GNP miktarının artmasıyla artış gösterdiği ve nanofiberlerin oluşumu esnasında çözücünün tamamen buharlaşmamış olması olabilir. PVB zincirlerine ve hidrojen bağlarından dolayı grafenlerin polar fonksiyonel gruplarına adsorbe edilen nanofiber içerisindeki hapsedilmiş çözücünün yavaş yavaş nanofiberden difüze edilmesi ve buharlaştırılması termal kararlılığın düşmesine neden olabilir.

\section{SONUÇ}

Ekonomik olarak uzun ve sürekli nanofiberlerin üretimi elektro-eğirme tekniğini önemli hale getirmektedir. En azından bu teknikle elde edilen nanofiberler birçok uygulama alanında kullanılmaktadırlar. Bu çalışmada, PVB polimer içerisine TEOS ve GNP katkılandırılarak elektro-eğirme tekniğiyle nanofiberlerin elde edilmesi başarılı bir şekilde gerçekleştirilmiştir. TEOS'un polimer içerisine ilave edilmesiyle PVB'nin çapraz bağlanılması gerçekleștirilerek TEOS/PVB nanofiber homojen bir şekilde elde edilmiştir. TEOS ve GNP ilavesinin çözeltinin viskozitesine ve iletkenliğine etki etmesi sonucunda nanofiber morfolojisinin yapısında değişimler gözlemlenmiştir. Elde edilen nanofiber boncuksuz, homojen yapıda olduğu ve nanofiberlerin ortalama çapları 150-500 nm arasında değişmekte olduğu gözlemlenmiştir. Ayrıca FTIR ve TGA analizleri yapılarak nanofiberlerin bağ etkileşimleri ve termal karalılıkları incelenmiştir. FTIR analizine göre ilave edilen malzemelerin pik şiddetlerinde değişime neden olurken TGA analizinde ise termal kararlılı̆ga olumsuz yönde etki ettiği görülmüştür. Elde edilen nanofiberler kompozit malzemelerin ara tabakasında, sensör uygulamalarında kullanılmak üzere daha birçok alanda uygulanma potansiyeline sahiptirler.

\section{KAYNAKLAR}

[1] Shao CL, Kim HY, Gong J, Ding B, Lee DR, Park SJ. Fiber mats of poly(vinyl alcohol)/silica composite via electrospinning. Mater Lett. 2003;57(9-10):1579-84.

[2] Zou H, Wu SS, Shen J. Polymer/silica nanocomposites: Preparation, characterization, properties, and applications. Chem Rev. 2008;108(9):3893-957.

[3] Larsen G, Velarde-Ortiz R, Minchow K, Barrero A, Loscertales IG. A method for making inorganic and hybrid (organic/inorganic) fibers and vesicles with diameters in the submicrometer and micrometer range via sol-gel chemistry and electrically forced liquid jets. J Am Chem Soc. 2003;125(5):1154-5.

[4] Wu SJ, Li FT, Wu YN, Xu R, Li GT. Preparation of novel poly(vinyl alcohol)/SiO2 composite nanofiber membranes with mesostructure and their application for removal of $\mathrm{Cu} 2+$ from waste water. Chem Commun. 2010;46(10):1694-6.

[5] Kulkarni SS, Kittur AA, Aralaguppi MI, Kariduraganavar MY. Synthesis and characterization of hybrid membranes using poly(vinyl alcohol) and tetraethylorthosilicate for the pervaporation separation of water-isopropanol mixtures. J Appl Polym Sci. 2004;94(3):1304-15.

[6] Li J, Suo JP, Deng RZ. Structure, Mechanical, and Swelling Behaviors of Poly(vinyl alcohol)/SiO2 
Hybrid Membranes. J Reinf Plast Comp. 2010;29(4):618-29.

[7] Chen LJ, Liao JD, Lin SJ, Chuang YJ, Fu YS. Synthesis and characterization of $\mathrm{PVB} /$ silica nanofibers by electrospinning process. Polymer. 2009;50(15):3516-21.

[8] Patel AC, Li SX, Yuan JM, Wei Y. In situ encapsulation of horseradish peroxidase in electrospun porous silica fibers for potential biosensor applications. Nano Lett. 2006;6(5):10426.

[9] Cannas C, Mainas M, Musinu A, Piccaluga G. $\mathrm{ZnO} / \mathrm{SiO} 2$ nanocomposites obtained by impregnation of mesoporous silica. Compos Sci Technol. 2003;63(8):1187-91.

[10] Loureiro SM, Ramos ML, Manoharan M. High temperature nanocomposite through engineered synthesis of hafnia nano-dispersoids in hexagonal mesoporous silica. J Am Ceram Soc. 2005;88(4):1072-5.

[11] Nagano T, Fujisaki S, Sato K, Hataya K, Iwamoto $\mathrm{Y}$, Nomura M, et al. Relationship between the mesoporous intermediate layer structure and the gas permeation property of an amorphous silica membrane synthesized by counter diffusion chemical vapor deposition. J Am Ceram Soc. 2008;91(1):71-6.

[12] Zhao MW, Kang WP, Zheng LQ, Gao YA. Synthesis of silica nanoboxes via a simple hardtemplate method and their application in controlled release. Mater Lett. 2010;64(8):990-2.

[13] Ji LW, Zhang XW. Ultrafine polyacrylonitrile/silica composite fibers via electrospinning. Mater Lett. 2008;62(14):2161-4.

[14] Greiner A, Wendorff JH. Electrospinning: A fascinating method for the preparation of ultrathin fibres. Angew Chem Int Edit. 2007;46(30):5670703.

[15] Li D, Xia YN. Electrospinning of nanofibers: Reinventing the wheel? Adv Mater. 2004;16(14):1151-70.

[16] Saquing CD, Manasco JL, Khan SA. Electrospun Nanoparticle-Nanofiber Composites via a One-Step Synthesis. Small. 2009;5(8):944-51.

[17] Bhardwaj N, Kundu SC. Electrospinning: A fascinating fiber fabrication technique. Biotechnol Adv. 2010;28(3):325-47.

[18] Gopal R, Kaur S, Ma ZW, Chan C, Ramakrishna S, Matsuura T. Electrospun nanofibrous filtration membrane. J Membrane Sci. 2006;281(1-2):581-6.

[19] Qi HX, Hu P, Xu J, Wang AJ. Encapsulation of drug reservoirs in fibers by emulsion electrospinning: Morphology characterization and preliminary release assessment. Biomacromolecules. 2006;7(8):2327-30.

[20] Ramaseshan R, Sundarrajan S, Jose R, Ramakrishna S. Nanostructured ceramics by electrospinning. J Appl Phys. 2007;102(11).

[21] Burger C, Hsiao BS, Chu B. Nanofibrous materials and their applications. Annu Rev Mater Res. 2006;36:333-68.

[22] Geltmeyer J, De Roo J, Van den Broeck F, Martins JC, De Buysser K, De Clerck K. The influence of tetraethoxysilane sol preparation on the electrospinning of silica nanofibers. J Sol-Gel Sci Techn. 2016;77(2):453-62.

[23] Lu HB, Yin JY, Xu B, Gou JH, Hui D, Fu YQ. Synergistic effects of carboxylic acidfunctionalized carbon nanotube and nafion/silica nanofiber on electrical actuation efficiency of shape memory polymer nanocomposite. Compos Part BEng. 2016;100:146-51.

[24] Wang HK, Yang XM, Wu QZ, Zhang QB, Chen HX, Jing HM, et al. Encapsulating Silica/Antimony into Porous Electrospun Carbon Nanofibers with Robust Structure Stability for High-Efficiency Lithium Storage. Acs Nano. 2018;12(4):3406-16.

[25] Zucker I, Dizge N, Fausey CL, Shaulsky E, Sun M, Elimelech M. Electrospun silica nanofiber mats functionalized with ceria nanoparticles for water decontamination. Rsc Adv. 2019;9(34):19408-17.

[26] Peltola T, Jokinen M, Veittola S, Rahiala H, YliUrpo A. Influence of sol and stage of spinnability on in vitro bioactivity and dissolution of sol-gelderived SiO2 fibers. Biomaterials. 2001;22(6):58998.

[27] Xu YD, Zhou WC, Zhang LT, Cheng LF. Spinnability and crystallizability of silica glass fiber by the sol-gel method. J Mater Process Tech. 2000;101(1-3):44-6.

[28] Feller RL, Curran M, Colaluca V, Bogaard J, Bailie C. Photochemical deterioration of poly (vinylbutyral) in the range of wavelengths from middle ultraviolet to the visible. Polym Degrad Stabil. 2007;92(5):920-31.

[29] Jahangiri S, Ozden-Yenigun E. The stability and dispersion of carbon nanotube-polymer solutions: A molecular dynamics study. J Ind Text. 2018;47(7):1568-83.

[30] Weng BC, Xu FH, Garza G, Alcoutlabi M, Salinas A, Lozano K. The Production of Carbon Nanotube Reinforced Poly(vinyl) Butyral Nanofibers by the Forcespinning (R) Method. Polym Eng Sci. 2015;55(1):81-7.

[31] Eskizeybek V, Yar A, Avci A. CNT-PAN hybrid nanofibrous mat interleaved carbon/epoxy laminates with improved Mode I interlaminar fracture toughness. Compos Sci Technol. 2018;157:30-9.

[32] Kaynan O, Atescan Y, Ozden-Yenigun E, Cebeci H. Mixed Mode delamination in carbon nanotube/nanofiber interlayered composites. Compos Part B-Eng. 2018;154:186-94.

[33] Papkov D, Zou Y, Andalib MN, Goponenko A, Cheng SZD, Dzenis YA. Simultaneously Strong and Tough Ultrafine Continuous Nanofibers. Acs Nano. 2013;7(4):3324-31.

[34] Ruenraroengsak P, Florence AT. The diffusion of latex nanospheres and the effective (microscopic) viscosity of HPMC gels. Int $J$ Pharmaceut. 2005;298(2):361-6.

[35] Zheng JF, He AH, Li JX, Xu JA, Han CC. Studies on the controlled morphology and wettability of polystyrene surfaces by electrospinning or electrospraying. Polymer. 2006;47(20):7095-102. 
[36] Wei Y, Feng QW, Xu JG, Dong H, Qiu KY, Jansen SA, et al. Polymethacrylate-silica hybrid nanoporous materials: A bridge between inorganic and polymeric molecular sieves. Adv Mater. 2000;12(19):1448-50.

[37] Wu XW, Mahalingam S, Amir A, Porwal H, Reece MJ, Naglieri V, et al. Novel Preparation, Microstructure, and Properties of PolyacrylonitrileBased Carbon Nanofiber-Graphene Nanoplatelet Materials. Acs Omega. 2016;1(2):202-11.

[38] Khan N, Kumar D, Kumar P. Microwave Assisted Synthesis of Polyvinylbutyral-silica Composites for Mercury Removal Application. Chemistryselect. 2019;4(6):1979-84.

[39] Ananth A, Arthanareeswaran G, Mok YS. Effects of in situ and ex situ formations of silica nanoparticles on polyethersulfone membranes. Polym Bull. 2014;71(11):2851-61.

[40] Wencel D, Dolan C, Barczak M, Keyes TE, McDonagh C. Synthesis, tailoring and characterization of silica nanoparticles containing a highly stable ruthenium complex. Nanotechnology. 2013;24(36).

[41] Chaudhry AU, Mittal V, Mishra B. Inhibition and promotion of electrochemical reactions by graphene in organic coatings. Rsc Adv. 2015;5(98):80365-8.

[42] Chuang YJ, Liao JD, Chen LJ. Polyvinylbutyralassisted synthesis and characterization of mesoporous silica nanofibers by electrospinning route. J Compos Mater. 2012;46(2):227-36.

[43] Hajian M, Reisi MR, Koohmareh GA, Jam ARZ. Preparation and characterization of Polyvinylbutyral/Graphene Nanocomposite. J Polym Res. 2012;19(10). 